Author affiliations appear at the end of this article.

Published online ahead of print at www.jco.org on August 3, 2015.

Supported only by the French Ministry of Health, through the National Institute for Cancer (INCa).

J.B. and M.S. contributed equally to this article.

Presented in part at the 83rd Annual Meeting of the American Thyroid Association, San Juan, Puerto Rico, October 16-20, 2013.

Authors' disclosures of potential conflicts of interest are found in the article online at www.jco.org. Author contributions are found at the end of this article.

Clinical trial information: NCT0435851.

Corresponding author: Isabelle Borget, PharmD, PhD, Biostatistics and Epidemiology, Gustave Roussy, 114 rue Edouard Vaillant, 94805 Villejuif, France e-mail: isabelle.borget@gustaveroussy .fr.

(C) 2015 by American Society of Clinical Oncology

0732-183X/15/3326w-2885w/\$20.00 DOI: 10.1200/JCO.2015.61.6722

\title{
Quality of Life and Cost-Effectiveness Assessment of Radioiodine Ablation Strategies in Patients With Thyroid Cancer: Results From the Randomized Phase III ESTIMABL Trial
}

Isabelle Borget, Julia Bonastre, Bogdan Catargi, Désirée Déandréis, Slimane Zerdoud, Daniela Rusu, Stéphane Bardet, Laurence Leenhardt, Delphine Bastie, Claire Schvartz, Pierre Vera, Olivier Morel, Daniele Benisvy, Claire Bournaud, Francoise Bonichon, Antony Kelly, Marie-Elisabeth Toubert, Sophie Leboulleux, Florence Journeau, Ellen Benhamou, and Martin Schlumberger

\section{$\begin{array}{llllllll}\text { A } & \text { B } & S & \text { T } & \text { R } & \text { A } & \text { C } & \text { T }\end{array}$}

\section{Purpose}

In the ESTIMABL phase III trial, the thyroid ablation rate was equivalent for the two thyroidstimulating hormone (TSH) stimulation methods (thyroid hormone withdrawal [THW] and recombinant human TSH [rhTSH]) and the two iodine-131 ( $\left.{ }^{131} \mathrm{I}\right)$ activities (1.1 or $\left.3.7 \mathrm{GBq}\right)$. The objectives of this article were to present health-related quality-of-life (HROoL) results and a costeffectiveness evaluation performed alongside this trial.

\section{Patients and Methods}

HRQoL and utility were longitudinally assessed, from random assignment to the follow-up visit at $8 \pm 2$ months for the 752 patients with thyroid cancer, using the Short Form-36 and the EuroQoL-5D questionnaires, respectively. A cost-effectiveness analysis was performed from the societal perspective in the French context. Resource use (hospitalization for ${ }^{131}$ I administration, rhTSH, sick leaves, and transportation) was collected prospectively. We used the net monetary benefit approach and computed cost-effectiveness acceptability curves for both TSH stimulation methods and ${ }^{131} \mathrm{I}$ activities. Sensitivity analyses of the costs of rhTSH were performed.

\section{Results}

At ${ }^{131} \mid$ administration, THW caused a clinically significant deterioration of HRQoL, whereas HRQoL remained stable with rhTSH. This deterioration was transient with no difference 3 months later. rhTSH was more effective than THW in terms of quality-adjusted life-years (QALYs; +0.013 QALY/patient) but more expensive (+€474/patient). The probability that rhTSH would be cost effective at $a € 50,000 /$ QALY threshold was $47 \%$ in France. The use of $1.1 \mathrm{GBq}$ of ${ }^{131} \mathrm{I}$ instead of 3.7 GBq reduced per-patient costs by $€ 955$ (US\$1,018) but with slightly decreased efficacy (-0.007 QALY/patient).

\section{Conclusion}

rhTSH avoids the transient THW-induced deterioration of HRQoL but is unlikely to be cost effective at its current price.

\section{J Clin Oncol 33:2885-2892. (C) 2015 by American Society of Clinical Oncology}

\section{INTRODUCTION}

Radioiodine (iodine-131 $\left[{ }^{131} \mathrm{I}\right]$ ) is administered to patients with thyroid cancer after total thyroidectomy to eradicate persistent normal or neoplastic thyroid tissue. ${ }^{1-3}$ This is ablation that is defined at $8 \pm 2$ months after radioiodine administration by the absence of abnormalities on neck ultrasonography and undetectable serum thyroglobulin levels. Stimulation by thyroid-stimulating hormone (TSH) is needed to promote iodine uptake by thyroid cells, and this is achieved either through thyroid hormone withdrawal (THW) for 3 to 5 weeks or recombinant human TSH (rhTSH) injections. In 2006, Pacini et $\mathrm{al}^{4}$ demonstrated similar efficacy between rhTSH and THW for ablation with $3.7 \mathrm{GBq}$ of ${ }^{131} \mathrm{I}$ in a noninferiority trial comprising 66 patients. Recently, the Etude Stimulation Ablation (ESTIMABL) phase III randomized trial comprising 752 French patients with thyroid cancer confirmed that the thyroid ablation rate was equivalent for the two methods of TSH stimulation (THW or rhTSH) 


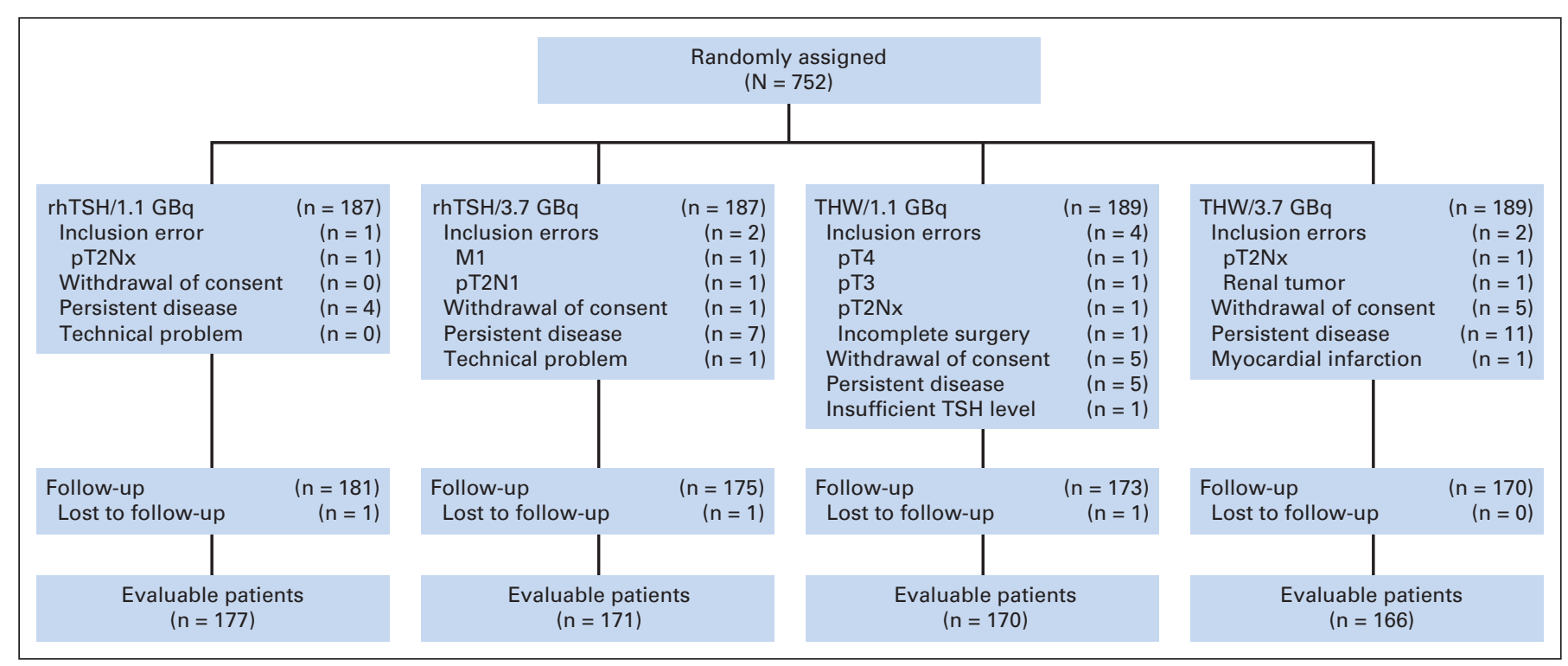

Fig 1. CONSORT diagram. rhTSH, recombinant human thyroid-stimulating hormone; TWH, thyroid hormone withdrawal.

and also for the two ${ }^{131}$ I activities $(1.1$ or $3.7 \mathrm{GBq}){ }^{5}$ Similar results were found in the HiLo (Multicentre Randomised Trial of High Dose Versus Low Dose Radioiodine, With or Without Recombinant Human Thyroid Stimulating Hormone, for Remnant Ablation Following Surgery for Differentiated Thyroid Cancer) phase III trial of 450 British patients. ${ }^{6}$

Hypothyroidism induced by THW is known to deteriorate the health-related quality of life (HRQoL). ${ }^{7-9}$ In the trial by Pacini et al, ${ }^{4}$ rhTSH avoided HRQoL deterioration induced by THW. However, the HRQoL evaluation was restricted to the periablation period. To date, the impact of iodine activity on HRQoL has not been evaluated.

rhTSH was shown to reduce the hospital stay ${ }^{10}$ and the duration of sick leaves ${ }^{11}$ in nonrandomized studies, making it possible to partially compensate its acquisition cost. However, the three cost-utility analyses based on Markov models that compared the use of either rhTSH or THW for ablation with $3.7 \mathrm{GBq}$ of ${ }^{131} \mathrm{I}$ yielded discordant results. ${ }^{12-14}$ Mernagh et al ${ }^{12}$ found that rhTSH was cost effective (the incremental cost-effectiveness ratio [ICER] of €958 per quality- adjusted life-year [QALY] was lower than the most commonly used $\$ 50,000 /$ QALY willingness-to-pay threshold) in the German context, and these results were confirmed in the Canadian setting (ICER, $\$ 1,520 /$ QALY) using the same model. ${ }^{13}$ In the US context, the use of rhTSH yielded an ICER of $\$ 52,554 / \mathrm{QALY} .{ }^{14}$ These studies were limited by the fact that data were either extracted from the literature (retrospective studies) or based on expert opinions. Sensitivity analyses showed that the greatest uncertainties concerned the duration of sick leaves and the length of hospital stays. ${ }^{15}$ Moreover, because life expectancy of patients with thyroid cancer is generally not shortened by the disease, QALY assessments are particularly relevant. The current literature is lacking rigorous data, and utility values have been rarely assessed using a standard preference-based questionnaire. ${ }^{16}$

Thyroid cancer has a significant economic and societal impact, with annual estimated costs of care exceeding \$1.6billion in the United States in 2013. ${ }^{17}$ Substantial costs are related to the diagnosis and treatment of newly diagnosed patients and to the ongoing follow-up in these patients with good prognosis. The clinical equivalence of the new radioiodine

\begin{tabular}{|c|c|c|}
\hline \multicolumn{3}{|l|}{ Drug } \\
\hline \multicolumn{3}{|l|}{ Hospital stay } \\
\hline Variable cost (per stay) & $€ 508$ & $\begin{array}{l}\text { French National Cost Survey, using the } 10 \mathrm{M} 121 \\
\text { diagnosis-related group code }\end{array}$ \\
\hline Ambulance & $€ 57+€ 2 / \mathrm{km}$ & French health insurance reimbursement tariffs \\
\hline Patient transport car & $€ 13+€ 1 / \mathrm{km}$ & \\
\hline Taxi & $€ 2+€ 1 / \mathrm{km}$ & \\
\hline Personal car & $€ 0.32 / \mathrm{km}$ & \\
\hline \multicolumn{3}{|l|}{ Indirect costs } \\
\hline Average daily wage (loss of productivity) & $€ 198$ per day & National added value per inhabitant \\
\hline
\end{tabular}




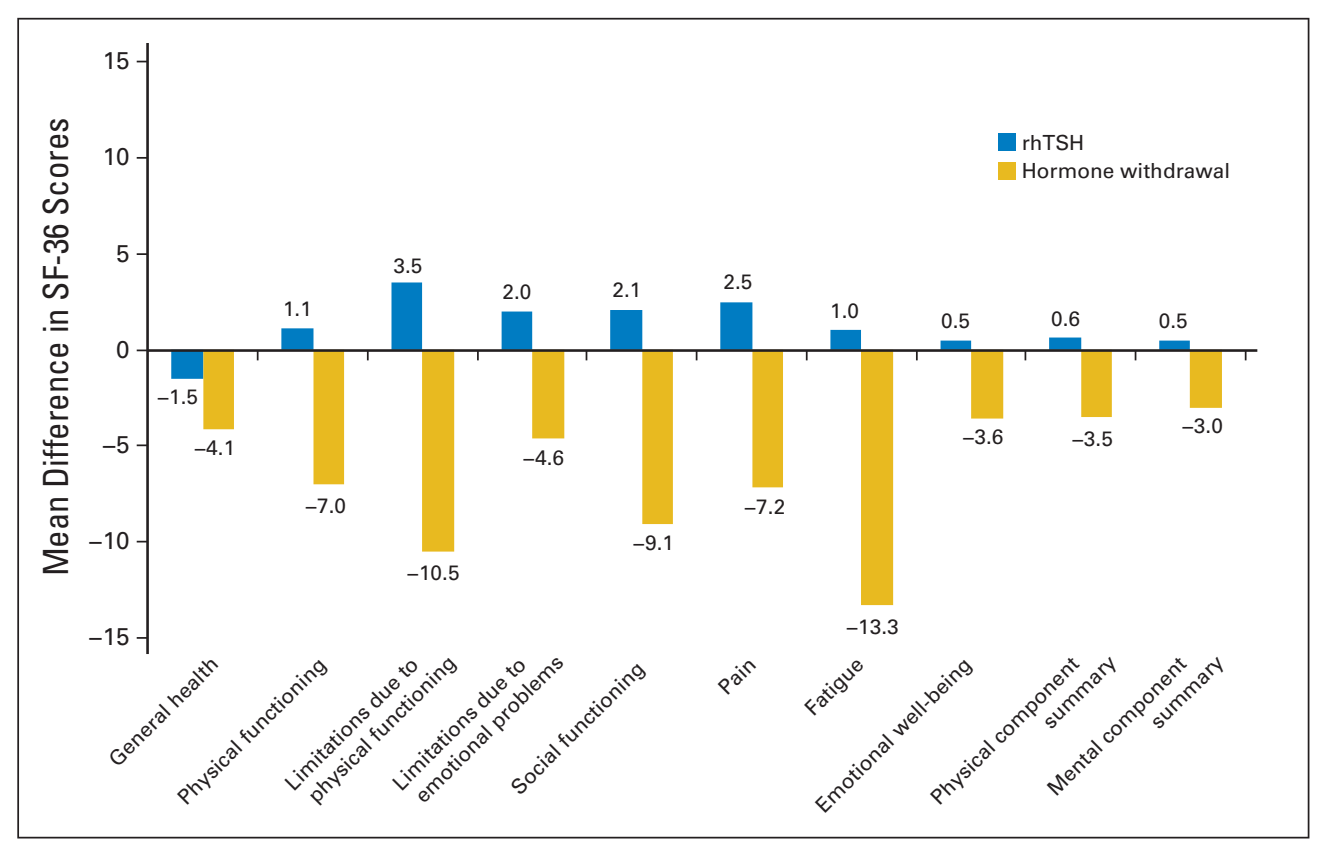

Fig 2. Mean difference in the Short Form (SF) -36 scores between random assignment and iodine administration, according to the thyroid-stimulating hormone (TSH) stimulation method. A significant difference in all SF-36 scores was observed between the two TSH stimulation methods at iodine-131 $\left({ }^{131} \mid\right)$ administration $(P<.001)$, particularly in the "Limitations due to physical functioning" and "Fatigue" dimensions. Thyroid hormone withdrawal (THW) caused a significant deterioration of health-related quality of life (HRQoL), whereas HRQoL was maintained in recombinant human TSH (rhTSH) patients. A higher proportion of patients in the THW groups reported clinically significant HRQoL deterioration at 131| administration compared with the rhTSH groups $(50 \% \vee 25 \%$, respectively, for physical component summary; $50 \% v$ $32 \%$, respectively, for mental component summary; both $P<.001$ ).

ablation strategies needs to be balanced against their impact on HRQoL and costs. By avoiding prolonged THW, rhTSH is expected to maintain HRQoL and decrease the duration of sick leave and hospital stay. Because rhTSH is an expensive drug, its routine use should be supported by an economic evaluation. Low radioiodine activity is expected to reduce the length of hospital stay, but its impact on HRQoL and cost-effectiveness is unknown. In this study, we present HRQoL findings and a costeffectiveness evaluation performed alongside the ESTIMABL trial.

\section{PATIENTS AND METHODS}

\section{ESTIMABL Trial Design}

We used patient-level data from the ESTIMABL trial (trial-based approach). This was a multicenter phase III trial where patients with thyroid cancer who underwent total thyroidectomy were randomly assigned to one of four strategies, with each strategy combining one TSH stimulation method (THW or rhTSH) and one ${ }^{131}$ I activity (1.1 or 3.7 GBq; Fig 1$) .{ }^{5}$ The trial was an equivalence study using a two-by-two factorial design to answer whether the successful ablation rate at $8 \pm 2$ months obtained with rhTSH was within $10 \%$ of that obtained with THW and the successful ablation rate with $1.1 \mathrm{GBq}$ of ${ }^{131} \mathrm{I}$ was within $10 \%$ of that obtained with $3.7 \mathrm{GBq}$. In the 684 evaluable patients, it was equivalent for both ${ }^{131}$ I activities and TSH stimulation methods. ${ }^{5}$ Secondary outcomes included HRQoL, hypothyroid symptoms and toxicities, direct and indirect costs, and cost-effectiveness.

\section{HRQoL and Utility}

Quality of life (QoL) was assessed using the self-administered Short Form-36 (SF-36; with an acute recall period) at random assignment (when all patients were euthyroid on 1-thyroxine therapy), immediately before ${ }^{131} \mathrm{I}$ administration, at 6 weeks after radioiodine administration, and at 3 and 8 months. The SF-36 questionnaire was used to describe the QoL because it has been shown to be sensitive in patients with thyroid cancer. ${ }^{4,7}$ At each visit, scores were allotted for the eight dimensions and for the physical component summary (PCS) and mental component summary (MCS). Clinically significant deterioration was defined as a decrease of 5 points or more in the PCS or MCS scores compared with the baseline scores. ${ }^{18}$ The proportion of patients with clinically significant deterioration was compared between treatments at each time point, using a $\chi^{2}$ test, with a corrected $P$ value for multiple testing. Logistic mixed models were used to assess the longitudinal impact of treatments on repeated measures of HRQoL, with the probability of having clinically significant deterioration on either PCS or MCS (successively) as a dependent variable. The models tested the treatment effect (either the TSH stimulation method or the ${ }^{131} \mathrm{I}$ activity successively), the time points (four visits after random assignment), and the interaction between treatment and time as fixed effects.

The EuroQoL (EQ) -5D questionnaire, a preference-based measure, was used to assess utility and QALYs. Questionnaires were collected seven times (at random assignment; immediately before ${ }^{131} \mathrm{I}$ administration; 2, 4, and 6 weeks

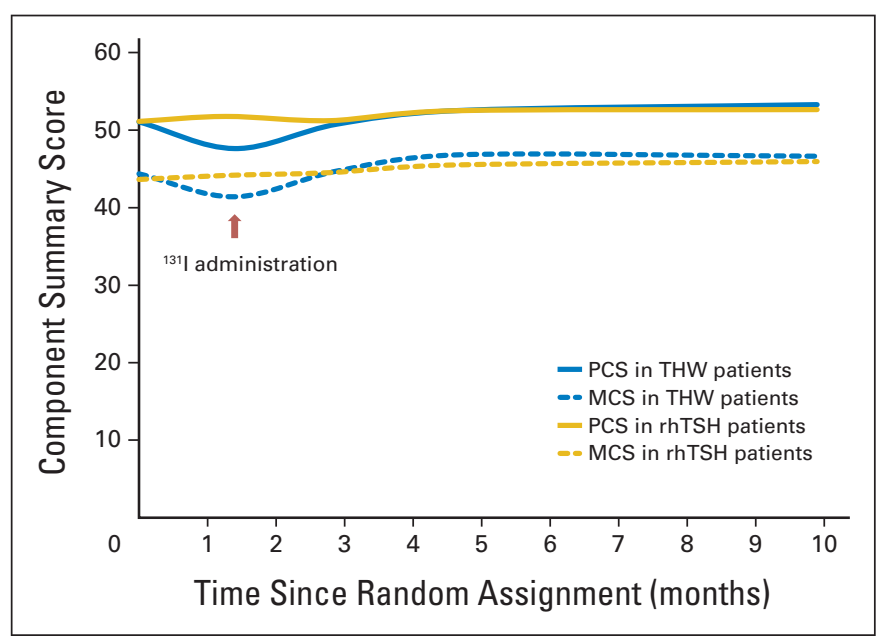

Fig 3. Evolution of the physical component summary (PCS) and mental component summary (MCS) scores during the follow-up period according to the thyroid-stimulating hormone (TSH) stimulation method. Ninety-seven percent of the expected Short Form-36 questionnaires were returned, whatever the visit or treatment group. Patients prepared by thyroid hormone withdrawal (THW) experienced deterioration on both PCS and MCS scores at the time of radioiodine $\left({ }^{131} \mathrm{I}\right)$ administration. Thereafter, health-related quality of life (HROoL) improved, and there was no difference in HRQoL between the two TSH stimulation methods 3 months later. rhTSH, recombinant human TSH. 
after radioiodine administration; and at the 3 - and 8-month visits) to measure the evolution of utility scores over that period. At each assessment, the utility value was obtained through the utility function, which was calculated based on the revealed preferences of the French population. ${ }^{19}$ For each patient, QALYs were assessed by weighting the time period between two consecutive visits with the utility value, assuming a linear change in utility over time (ie, using a trapezoidal area formula). QALYs were obtained by summing values for each time interval and were adjusted for unbalanced baseline values between groups. ${ }^{20}$

\section{Resource Use and Costs}

Resource use was prospectively collected alongside the ESTIMABL trial until the thyroid ablation assessment at 8 months. It included hospitalization for ${ }^{131} \mathrm{I}$ administration, rhTSH, sick leaves, and transportation. Costs were assessed from the French societal perspective and were expressed in 2013 euros (results are also presented in US dollars using the conversion rate of $€ 1=$ US\$1.066). Unit costs data are listed in Table 1. rhTSH was used for radioiodine administration exclusively in the rhTSH groups (two vials) and in all patients during the visit at 8 months (two vials). To account for the economic impact of the reduction in the length of hospital stay, the cost per stay was calculated distinguishing between fixed costs per day (staff, equipment, and overhead) and variable costs per stay (resources required for ${ }^{131} \mathrm{I}$ administration, rhTSH, and radioiodine activity). Fixed and variable costs were extracted from the French National Cost Survey, using the diagnosis-related group code for ${ }^{131} \mathrm{I}$ administration. The price of rhTSH was obtained from the French drug database. ${ }^{21}$ Indirect costs were evaluated based on the loss of productivity incurred by sick leave using the friction cost approach. One day off work translated into 0.8 day of lost productivity to adapt the adjustment time period to absenteeism. ${ }^{22,23}$ The value of lost productivity was based on the national added value estimated at $€ 198$ (US\$211) per day. Transportation costs were estimated using the French health insurance reimbursement tariffs, according to the home-hospital distance and the type of transportation used. Mean cost per patient was calculated with and without indirect costs, according to the French guidelines for cost-effectiveness studies. ${ }^{24}$ Mean costs were compared between groups using nonparametric Wilcoxon tests.

\section{Cost-Effectiveness Analysis}

The time horizon was fixed at $8 \pm 2$ months because no difference in utility scores or costs between strategies was expected after thyroid ablation assessment. Whatever the strategy, all patients had the same life expectancy (no death occurred during the 8-month period).

We used the net monetary benefit approach to compare the stimulation methods and the radioiodine activities. ${ }^{25}$ A nonparametric bootstrap with 10,000 replications (percentile method) was used to estimate the $95 \%$ CIs for costs, QALYs, and cost-effectiveness acceptability curves. A one-way sensitivity analysis was performed reducing the price of rhTSH by $10 \%$ and $30 \%$, because a biosimilar of rhTSH may be available in the future.

Table 2. Descriptive Results Obtained With the EuroQol-5D at Radioiodine Ablation by Method of Stimulation and Radioiodine Activity

\begin{tabular}{|c|c|c|c|c|}
\hline \multirow[b]{3}{*}{ Dimension and Level } & \multicolumn{4}{|c|}{ No. of Patients (\%) } \\
\hline & \multicolumn{2}{|c|}{ TSH Stimulation Method } & \multicolumn{2}{|c|}{ Radioiodine Activity } \\
\hline & THW $(n=336)$ & rhTSH (n = 348) & $3.7 \mathrm{GBq}(\mathrm{n}=337)$ & $1.1 \mathrm{GBq}(\mathrm{n}=347)$ \\
\hline \multicolumn{5}{|l|}{ Mobility } \\
\hline No problems (1) & $292(86.9)$ & $325(93.4)$ & $307(91.1)$ & $310(89.3)$ \\
\hline Some problems (2) & 39 (11.6) & $21(6.0)$ & $29(8.6)$ & $31(8.9)$ \\
\hline Confined to bed (3) & $1(0.3)$ & $1(0.3)$ & $1(0.3)$ & $1(0.3)$ \\
\hline Missing & $4(1.2)$ & $1(0.3)$ & $0(0)$ & $5(1.4)$ \\
\hline \multicolumn{5}{|l|}{ Self-care } \\
\hline No problems (1) & $327(97.3)$ & $342(98.3)$ & $332(98.5)$ & $337(97.1)$ \\
\hline Some problems (2) & $5(1.5)$ & $5(1.4)$ & $5(1.5)$ & $5(1.4)$ \\
\hline Unable to (3) & $0(0)$ & $0(0)$ & $0(0)$ & $0(0)$ \\
\hline Missing & $4(1.2)$ & $1(0.3)$ & $0(0)$ & $5(1.4)$ \\
\hline \multicolumn{5}{|l|}{ Usual activities } \\
\hline No problems (1) & $264(78.6)$ & $299(85.9)$ & $278(82.5)$ & $285(82.1)$ \\
\hline Some problems (2) & $65(19.3)$ & 45 (12.9) & $56(16.6)$ & $54(15.6)$ \\
\hline Extreme (3) & $3(0.9)$ & $2(0.6)$ & $3(0.9)$ & $2(0.6)$ \\
\hline Missing & $4(1.2)$ & $2(0.6)$ & $0(0)$ & $6(1.7)$ \\
\hline \multicolumn{5}{|l|}{ Pain discomfort } \\
\hline None (1) & $186(55.4)$ & $203(58.3)$ & $188(55.8)$ & $201(57.9)$ \\
\hline Moderate (2) & $138(41.1)$ & $137(39.4)$ & $140(41.5)$ & $135(38.9)$ \\
\hline Extreme (3) & $8(2.4)$ & $6(1.7)$ & $9(2.7)$ & $5(1.4)$ \\
\hline Missing & $4(1.2)$ & $2(0.6)$ & $0(0)$ & $6(1.7)$ \\
\hline \multicolumn{5}{|l|}{ Anxiety/depression } \\
\hline None (1) & $162(48.2)$ & $157(45.1)$ & $156(46.3)$ & $163(47.0)$ \\
\hline Moderate (2) & $161(47.9)$ & $172(49.4)$ & 168 (49.9) & $165(47.6)$ \\
\hline Extreme (3) & $9(2.7)$ & $18(5.2)$ & $13(3.9)$ & $14(4.0)$ \\
\hline Missing & $4(1.2)$ & $1(0.3)$ & $0(0)$ & $5(1.4)$ \\
\hline Patients in perfect health state (all levels $=1$ ) & $100(29.8)$ & $100(28.7)$ & $98(29.0)$ & $102(29.4)$ \\
\hline \multicolumn{5}{|l|}{ Utility score } \\
\hline Mean & 0.833 & 0.849 & 0.836 & 0.846 \\
\hline Standard deviation & 0.192 & 0.173 & 0.184 & 0.182 \\
\hline Range & -0.302 to 1.000 & -0.018 to 1.000 & -0.018 to 1.000 & -0.302 to 1.000 \\
\hline
\end{tabular}




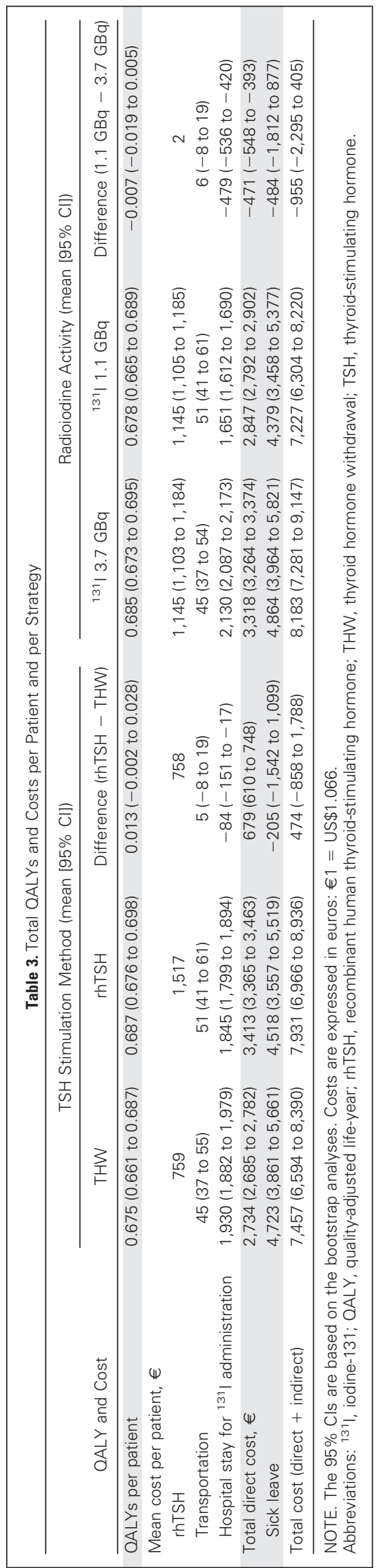




\section{Statistical Analysis}

Analyses of HRQoL and cost-effectiveness were performed according to the $2 \times 2$ factorial design on the 684 evaluable patients for the main outcome. ${ }^{5}$ The number of patients required in the ESTIMABL trial was not calculated to detect a difference in the MCS or PCS score. However, this number allowed the detection of a minimal difference of $13 \%$. The analyses were performed using the SAS software version 9.1 (SAS Institute, Cary, NC).

\section{RESULTS}

\section{HRQoL}

Ninety-seven percent of the expected SF-36 questionnaires were returned. Patients who had undergone THW exhibited a significant deterioration $(P<.001)$ of HRQoL at ${ }^{131} \mathrm{I}$ administration compared with rhTSH patients (Fig 2). The greatest deterioration was observed in physical health-related and vitality domains, but all domains were significantly affected. A higher proportion of patients reported clinically significant HRQoL deterioration at ${ }^{131} \mathrm{I}$ administration in the THW groups compared with the rhTSH groups $(50 \% v 25 \%$, respectively, for PCS; 50\% $v 32 \%$, respectively, for MCS; both $P<.001$ ). Thereafter, HRQoL improved, and no significant difference in HRQoL scores was observed at subsequent follow-up visits (Fig 3). ${ }^{131}$ I activity did not have any impact on HRQoL.

Using the EQ-5D questionnaire, at ${ }^{131} \mathrm{I}$ administration, THW patients had significantly more problems with mobility and usual activities than rhTSH patients, translating into a lower utility score (estimated at 0.833 and 0.849 , respectively; Table 2). Utility scores of THW patients continued to decrease for 2 weeks after radioiodine administration and then increased; a similar evolution was observed with utility scores obtained from SF-36 questionnaires (Appendix Fig Al, online only). Over 8 months, mean QALY reached 0.675 and 0.687 per patient stimulated by THW or rhTSH, respectively. Because there was no difference in survival, the QALY difference was only explained by the utility values.

\section{Resource Use and Costs}

The length of hospital stay for ${ }^{131} \mathrm{I}$ administration was similar in the rhTSH and THW groups ( $2.6 v 2.8$ days, respectively), as was sick leave time ( $23 v 24$ days, respectively). Concerning the radioiodine activity, the length of hospital stay was significantly shorter in patients receiving $1.1 \mathrm{GBq}$ compared with $3.7 \mathrm{GBq}(2.3 v 3.2$ days, respectively; $P<.001$ ), but no difference was observed in the length of sick leaves ( $22 v 25$ days, respectively). There was no difference in the type of transportation.

Mean direct costs were estimated at $€ 3,413$ (US $\$ 3,638$ ) per rhTSH patient and $€ 2,734$ (US\$2,914) per THW patient. The use of rhTSH was associated with an extra cost of $€ 679$ per patient, mainly as a result of its price. Mean direct cost was lower in patients treated with $1.1 \mathrm{GBq}$ than with $3.7 \mathrm{GBq}(€ 2,847$ and $€ 3,318$, respectively) as a result of a shorter hospital stay (Table 3).

\section{Cost-Effectiveness Analysis}

Over the 8-month period, the use of rhTSH was more effective in terms of QALYs (mean increase of 0.013 QALY per patient) but was more expensive than THW (Table 3). With the threshold of $€ 50,000$ / QALY (US\$53,300/QALY), the probability that rhTSH would be cost effective was $47 \%$ and $59 \%$ when direct and total (direct plus indirect) costs were considered, respectively (Fig 4 and Appendix Fig A2, online only). When the rhTSH price was lowered by $30 \%$, the extra cost incurred with rhTSH was reduced ( $€ 452$ for direct costs) and the probability that rhTSH would be cost effective for a threshold of $€ 50,000 / \mathrm{QALY}$ increased to 70\% (Appendix Fig A4, online only).

The use of $1.1 \mathrm{GBq}$ instead of $3.7 \mathrm{GBq}$ of ${ }^{131}$ I led to a small decline in QALYs (mean decrease of 0.007 QALY) but was also cheaper (Table 3). At the threshold of $€ 50,000 / \mathrm{QALY}$, the probability that the lower ${ }^{131} \mathrm{I}$ activity would be cost effective was $65 \%$ and $77 \%$ when direct and total costs were considered, respectively (Appendix Figs A2 and A3).

\section{DISCUSSION}

At ${ }^{131} \mathrm{I}$ administration, HRQoL was significantly better in all the SF-36 domains for rhTSH patients than after THW, ${ }^{7,8}$ because rhTSH avoids hypothyroidism. This effect was transient, and there was no difference in HRQoL 3 months after ${ }^{131}$ I administration. Given the current price of rhTSH, it is unlikely to be cost effective at a threshold of $€ 50,000 /$ QALY. The availability of an rhTSH biosimilar in the future will probably allow a price reduction and better value for money. Regarding radioiodine activity, there was no impact on HRQoL, but cost-effectiveness results favor the use of a low ${ }^{131}$ I activity because it shortened the length of hospital stay.

Cost-effectiveness analyses on the use of rhTSH have reported heterogeneous results in the literature. Mernagh et $\mathrm{al}^{12}$ found that rhTSH was cost effective (ICER, €958/QALY) in the German context, using a Markov model and a lifetime horizon. The greatest uncertainty in this model was the long-term development of second malignancies. Applying the same model in the Canadian context, rhTSH remained

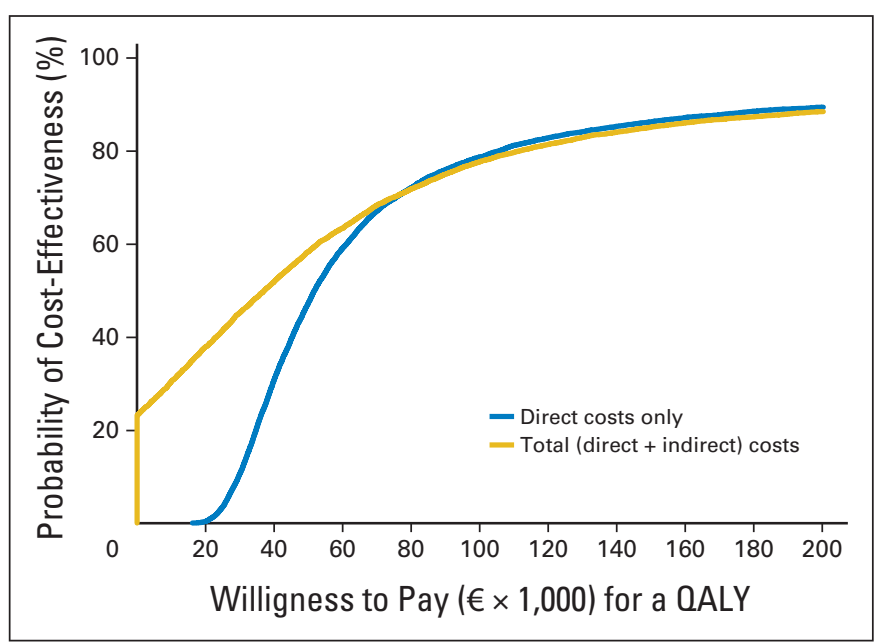

Fig 4. Acceptability curves of recombinant human thyroid-stimulating hormone (rhTSH) compared with thyroid hormone withdrawal (THW). Costeffectiveness acceptability curve using net-monetary benefit approach $(10,000$ bootstrap replicates) represents the probability ( $y$-axis) that rhTSH is more cost effective compared with THW at the range of willingness-to-pay thresholds (euros per quality-adjusted life-year [QALY]) on the $x$-axis. By repeating this procedure for various thresholds, a curve is generated, with a threshold on the $x$-axis and probability of rhTSH to be cost effective on the $y$-axis. Acceptability curves are presented here taking into account direct costs only or total (direct and indirect) costs. 
highly cost effective, with an ICER of $\$ 1,520 / \mathrm{QALY} .^{13}$ This study, which used a 17-week time horizon and excluded second malignancies, was sensitive to the rhTSH price and to the lengths of hospital stays and sick leaves. In the US context, the ICER of rhTSH was $\$ 52,554 /$ QALY over a 4 -year period, and results were sensitive to patient utility during the first weeks after the thyroidectomy, a change in sick leave, and rhTSH cost. ${ }^{14}$ Differences in cost-effectiveness results may be explained by the clinical and economic inputs included in these economic evaluations. First, the three previous models used utility scores based on SF-36 data (transformed into SF-6D scores). ${ }^{16}$ In these models, the difference in utility scores between THW and rhTSH reached 0.17 at radioiodine administration. It was lower in our study, thus reducing the probability of rhTSH to be cost effective. Indeed, the duration of sick leave was estimated at 11 days for THW patients and 6.5 days (hypothesis of a $50 \%$ reduction) for rhTSH patients in the studies by Mernagh et al. ${ }^{12,13}$ Using this hypothesis, the incremental cost of the rhTSH strategy was low ( $€ 47$ and $\$ 87$ per patient in the German and Canadian contexts, respectively). The cost of rhTSH injections was outweighed by the reduction in sick leave and hospital stay costs. In our study, sick leave was only shortened by 1 day, leading to a higher incremental cost of using rhTSH (€474) and a low probability of cost-effectiveness. Finally, differences may also be explained by the time horizon. Unlike the study by Mernagh et al, ${ }^{12}$ our study did not consider the impact of treatment on the risk of second malignancies because the development of second malignancies after a single ${ }^{131}$ I administration ${ }^{13}$ remains controversial.

Our study has several strengths. First, data for the HRQoL analysis and the economic evaluation were prospectively collected alongside a phase III randomized trial at the patient level in the 24 participating centers, and the 684 patients were representative of patients scheduled for ${ }^{131}$ I ablation in the routine clinical setting. Second, the ESTIMABL trial provides unbiased estimates of the length of hospital stay for ablation, the duration of sick leaves, and health state utilities, input parameters that were associated with the greatest uncertainties in previous modeling studies. Third, our study has the longest longitudinal collection of HRQoL data during the initial management of patients with differentiated thyroid cancer. In previous studies, HRQoL was measured over only 2 months after a thyroidectomy. Indeed, our study was the first to prospectively assess utility values using the EQ-5D questionnaire, as recommended by health technology assessment agencies in the United States (Agency for Healthcare Research and Quality) ${ }^{26}$ and Europe (National Institute for Health and Care Excellence, Haute Autorité de Santé). ${ }^{24,27}$ Fourth, the $2 \times 2$ factorial design allowed us to address whether ablation preparation with rhTSH versus THW and the use of 1.1 GBq instead of $3.7 \mathrm{GBq}$ exert an impact on HRQoL and costeffectiveness in one study.

Our study also has limitations. First, the EQ-5D was found to be less sensitive in the oncology setting, especially in situations where the degree of vitality is an important element. ${ }^{28}$ The EQ-5D tool does not capture small changes in health that are often important in HRQoL of patients with cancer. In the context of thyroid cancer where vitality/ fatigue is the most impacted domain by hypothyroidism, this lack of sensitivity of the EQ-5D questionnaire may explain the small difference in QALYs between rhTSH and THW. Second, the willingnessto-pay threshold for cost-effectiveness analyses is not well defined, depending on societal judgment and available resources of the country. A threshold of approximately $\mathfrak{E} 30,000 / \mathrm{QALY}$ has been applied in the United Kingdom ${ }^{29}$; it reached $\$ 50,000 /$ QALY in the United States $^{30}$; and there is no official threshold in France. ${ }^{24}$ Here, costeffectiveness results were presented for a $€ 50,000 / Q A L Y$ threshold, a well-accepted threshold in France, and using acceptability curves. Third, some data may be specific to the French context. The length of hospital stay reflected the inpatient management for ${ }^{131}$ I administration in French centers. The French sick leave compensation system may explain the long period of sick leave. However, because the cost differences for the hospital stay and sick leave were small, the impact of outpatient management or a sick leave reduction is expected to be low.

Given their unique trends in incidence and survival, costs in patients with thyroid cancer exhibit a distinct pattern compared with patients with other cancer types; $78 \%$ of the cost is incurred during initial treatment and subsequent follow-up. ${ }^{17}$ With the projected increased incidence and survival trends, costs will continue to escalate. Therefore, it is essential to assess the efficiency of the initial treatment phase. Our study showed that the main advantage of rhTSH is to avoid the transient THW-induced decline in HRQoL. However, this QoL benefit did not outweigh the cost of rhTSH, and the rhTSH strategy was not cost effective for standard thresholds in the French context. rhTSH would be cost effective if its price was lowered by $30 \%$. Regarding iodine activity, cost-effectiveness results favor using a low ${ }^{131} \mathrm{I}$ activity, which reduces the length of hospital stay for ablation and overall management costs.

\section{AUTHORS' DISCLOSURES OF POTENTIAL CONFLICTS} OF INTEREST

Disclosures provided by the authors are available with this article at www.jco.org.

\section{AUTHOR CONTRIBUTIONS}

\section{Conception and design: Julia Bonastre, Ellen Benhamou, Martin} Schlumberger

Collection and assembly of data: Isabelle Borget, Bogdan Catargi, Désirée Déandréis, Slimane Zerdoud, Daniela Rusu, Stéphane Bardet, Laurence Leenhardt, Delphine Bastie, Claire Schvartz, Pierre Vera, Olivier Morel, Danielle Benisvy, Claire Bournaud, Francoise Bonichon, Antony Kelly, Marie-Elisabeth Toubert, Sophie Leboulleux, Ellen Benhamou, Martin Schlumberger

Data analysis and interpretation: Isabelle Borget, Julia Bonastre, Florence Journeau, Ellen Benhamou, Martin Schlumberger

Manuscript writing: All authors

Final approval of manuscript: All authors

\section{REFERENCES}

1. Schlumberger MJ: Papillary and follicular thy roid carcinoma. N Engl J Med 338:297-306, 1998

2. Pacini $F$, Schlumberger $M$, Dralle $H$, et al: European consensus for the management of pa- tients with differentiated thyroid carcinoma of the follicular epithelium. Eur J Endocrinol 154:787-803, 2006

3. American Thyroid Association (ATA) Guidelines Taskforce on Thyroid Nodules and Differentiated Thyroid Cancer, Cooper DS, Doherty GM, et al: Revised American Thyroid Association management guidelines for patients with thyroid nodules and differentiated thyroid cancer. Thyroid 19:1167-1214, 2009

4. Pacini F, Ladenson PW, Schlumberger $M$, et al: Radioiodine ablation of thyroid remnants after preparation with recombinant human thyrotropin in differentiated thyroid carcinoma: Results of an international, randomized, controlled study. J Clin 
Endocrinol Metab 91:926-932, 2006

5. Schlumberger M, Catargi B, Borget I, et al: Strategies of radioiodine ablation in patients with low-risk thyroid cancer. N Engl J Med 366:16631673, 2012

6. Mallick U, Harmer C, Yap B, et al: Ablation with low-dose radioiodine and thyrotropin alfa in thyroid cancer. N Engl J Med 366:1674-1685, 2012

7. Schroeder PR, Haugen BR, Pacini $F$, et al: $A$ comparison of short-term changes in health-related quality of life in thyroid carcinoma patients undergoing diagnostic evaluation with recombinant human thyrotropin compared with thyroid hormone with drawal. J Clin Endocrinol Metab 91:878-884, 2006

8. Luster M, Felbinger $R$, Dietlein $M$, et al: Thyroid hormone withdrawal in patients with differentiated thyroid carcinoma: A one hundred thirty-patient pilot survey on consequences of hypothyroidism and a pharmacoeconomic comparison to recombinant thyrotropin administration. Thyroid 15:1147-1155, 2005

9. Lee J, Yun MJ, Nam KH, et al: Quality of life and effectiveness comparisons of thyroxine withdrawal, triiodothyronine withdrawal, and recombinant thyroid-stimulating hormone administration for low-dose radioiodine remnant ablation of differentiated thyroid carcinoma. Thyroid 20:173-179, 2010

10. Borget I, Remy H, Chevalier J, et al: Length and cost of hospital stay of radioiodine ablation in thyroid cancer patients: Comparison between preparation with thyroid hormone withdrawal and thyrogen. Eur J Nucl Med Mol Imaging 35:1457-1463, 2008

11. Borget I, Corone C, Nocaudie M, et al: Sick leave for follow-up control in thyroid cancer patients: Comparison between stimulation with Thyrogen and thyroid hormone withdrawal. Eur J Endocrino 156:531-538, 2007
12. Mernagh $P$, Campbell $S$, Dietlein $M$, et al: Cost-effectiveness of using recombinant human TSH prior to radioiodine ablation for thyroid cancer, compared with treating patients in a hypothyroid state: The German perspective. Eur J Endocrinol 155:405-414, 2006

13. Mernagh $P$, Suebwongpat $A$, Silverberg J, et al: Cost-effectiveness of using recombinant human thyroid-stimulating hormone before radioiodine ablation for thyroid cancer: The Canadian perspective. Value Health 13:180-187, 2010

14. Wang TS, Cheung K, Mehta $P$, et al: To stimulate or withdraw? A cost-utility analysis of recombinant human thyrotropin versus thyroxine withdrawal for radioiodine ablation in patients with low-risk differentiated thyroid cancer in the United States. J Clin Endocrinol Metab 95:1672-1680, 2010

15. Ramsey $S$, Willke $R$, Briggs $A$, et al: Good research practices for cost-effectiveness analysis alongside clinical trials: The ISPOR RCT-CEA Task Force report. Value Health 8:521-533, 2005

16. Brazier J, Usherwood T, Harper R, et al: Deriving a preference-based single index from the UK SF-36 Health Survey. J Clin Epidemiol 51:1115-1128, 1998

17. Lubitz CC, Kong CY, McMahon PM, et al: Annual financial impact of well-differentiated thyroid cancer care in the United States. Cancer 120:13451352, 2014

18. Revicki DA, Cella D, Hays RD, et al: Responsiveness and minimal important differences for patient reported outcomes. Health Qual Life Outcomes 4:70, 2006

19. Chevalier J, de Pouvourville G: Valuing EQ-5D using time trade-off in France. Eur $\mathrm{J}$ Health Econ 14:57-66, 2013

20. Manca A, Hawkins N, Sculpher MJ: Estimating mean QALYs in trial-based cost-effectiveness analysis: The importance of controlling for baseline utility. Health Econ 14:487-496, 2005

21. Caisse Nationale d'Assurance Maladie et des Travailleurs Sociaux: Base des médicaments et informations tarifaires. http://www.codage.ext.cnamts.fr/codif/bdm// fiche/l

22. Koopmanschap MA, Rutten FF, van Ineveld $B M$, et al: The friction cost method for measuring indirect costs of disease. J Health Econ 14:171-189, 1995

23. Liljas B: How to calculate indirect costs in economic evaluations. Pharmacoeconomics 13:1-7, 1998

24. Haute Autorité de Santé: Choix méthodologiques pour l'évaluation économique à la HAS. http://www.hassante.fr/portail/jcms/r_1499251/en/choices-in-methodsfor-economic-evaluation

25. Briggs $\mathrm{AH}$ : Handling uncertainty in costeffectiveness models. Pharmacoeconomics 17:479500, 2000

26. Agency for Healthcare Research and Quality: US valuation of the EuroOol EQ-5 Health States. http:// www.ahrq.gov/professionals/clinicians-providers/ resources/rice/EQ5Dproj.html

27. National Institute for Health and Care Excellence: Guide to the methods of technology appraisal 2013, foreword: Guidance and guidelines. http:// www.nice.org.uk/article/PMG9/chapter/Foreword

28. Garau M, Shah KK, Mason $A R$, et al: Using QALYs in cancer: A review of the methodological limitations. Pharmacoeconomics 29:673-685, 2011

29. Rawlins MD, Culyer AJ: National Institute for Clinical Excellence and its value judgments. BMJ 329:224-227, 2004

30. Neumann PJ, Cohen JT, Weinstein MC: Updating cost-effectiveness: The curious resilience of the \$50,000-per-QALY threshold. N Engl J Med $371: 796-797,2014$

\section{Affiliations}

Isabelle Borget, Julia Bonastre, Désirée Déandréis, Sophie Leboulleux, Florence Journeau, Ellen Benhamou, and Martin Schlumberger, Gustave Roussy, Villejuif; Isabelle Borget, Julia Bonastre, and Ellen Benhamou, Center for Research in Epidemiology and Population Health, L'Institut National de la Santé et de la Recherche Médicale 1018; Isabelle Borget and Martin Schlumberger, University Paris-Sud; Laurence Leenhardt, Hôpital Pitié-Salpétrière; Marie-Elisabeth Toubert, Hôpital Saint-Louis, Paris; Bogdan Catargi, Centre Hospitalier Universitaire (CHU) Bordeaux; Francoise Bonichon, Institut Bergonié, Bordeaux; Slimane Zerdoud, Centre Claudius Regaud; Delphine Bastie, CHU Toulouse, Toulouse; Daniela Rusu, Centre René Gauducheau, Nantes; Stéphane Bardet, Centre François Baclesse, Caen; Claire Schvartz, Institut Jean Godinot, Reims; Pierre Vera, Centre Becquerel, Rouen; Olivier Morel, Institut de Cancérologie de l'Ouest, Paul Papin, Angers; Daniele Benisvy, Centre Lacassagne, Nice; Claire Bournaud, CHU Lyon, Lyon; and Antony Kelly, Centre Jean Perrin, Clermont-Ferrand, France. 


\section{AUTHORS' DISCLOSURES OF POTENTIAL CONFLICTS OF INTEREST}

Quality of Life and Cost-Effectiveness Assessment of Radioiodine Ablation Strategies in Patients With Thyroid Cancer: Results From the Randomized Phase III ESTIMABL Trial

The following represents disclosure information provided by authors of this manuscript. All relationships are considered compensated. Relationships are self-held unless noted. I = Immediate Family Member, Inst = My Institution. Relationships may not relate to the subject matter of this manuscript. For more information about ASCO's conflict of interest policy, please refer to www.asco.org/rwc or jco.ascopubs.org/site/ifc.

Isabelle Borget

Honoraria: Roche, Janssen-Cilag

Travel, Accommodations, Expenses: Janssen-Cilag

\section{Julia Bonastre}

No relationship to disclose

\section{Bogdan Catargi}

No relationship to disclose

\section{Désirée Déandréis}

No relationship to disclose

\section{Slimane Zerdoud}

No relationship to disclose

\section{Daniela Rusu}

No relationship to disclose

Stéphane Bardet

Honoraria: Genzyme

Laurence Leenhardt

Honoraria: Sanofi, Genzyme

Consulting or Advisory Role: Sanofi, Genzyme

Delphine Bastie

No relationship to disclose

\section{Claire Schvartz}

No relationship to disclose

Pierre Vera

No relationship to disclose
Olivier Morel

No relationship to disclose

Danielle Benisvy

No relationship to disclose

Claire Bournaud

Travel, Accommodations, Expenses: Genzyme

Francoise Bonichon

No relationship to disclose

\section{Antony Kelly}

Travel, Accommodations, Expenses: Novartis, Genzyme

Marie-Elisabeth Toubert

No relationship to disclose

Sophie Leboulleux

Honoraria: Genzyme, Sanofi

Research Funding: Genzyme, Sanofi

Florence Journeau

No relationship to disclose

Ellen Benhamou

Honoraria: GE Healthcare

Martin Schlumberger

Honoraria: Genzyme

Consulting or Advisory Role: Genzyme 


\section{Acknowledgment}

We thank the following for their help in this work: the French Tumeurs de la Thyroide Refractaire à l'Iode network of refractory thyroid cancer, Gerard de Pourvouville for the study protocol, Sylviane Iacobelli for data management, Muriel Wartelle and Pascal Jan for informatics assistance, Lorna Saint Ange for editing, Sophie Marguet for help to respond to peer reviewers' comments in a timely manner, Dana Hartl for rereading, and John Brazier for providing the algorithm transforming Short Form-36 scores into utility values.

\section{Appendix}

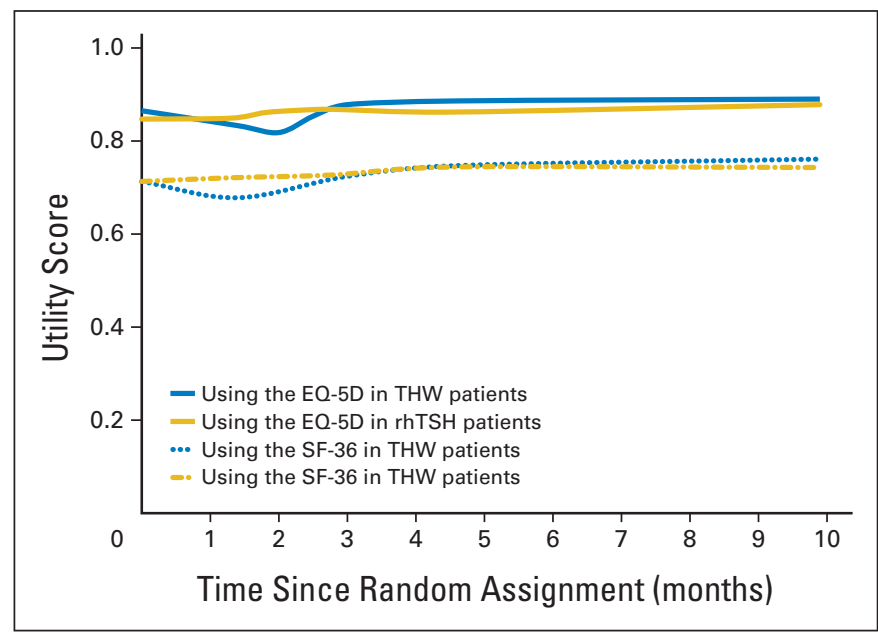

Fig A1. Evolution of the utility scores during the follow-up period obtained with the EuroQol (EQ) -5D and the Short Form (SF) - 36 questionnaires (transformed in utility score using the algorithm developed by Brazier et $\mathrm{al}^{16}$ ) by thyroid-stimulating hormone (TSH) stimulation method. Utility scores using the SF-36 questionnaire are lower than those based on the EQ-5D questionnaire. However, the evolution of the utility scores over the 8-month period is similar whatever the tool, as is the difference in quality-adjusted life-years (QALYs) between thyroid hormone withdrawal (THW) and recombinant human TSH (rhTSH; estimated at 0.538 and 0.544 , respectively; difference of 0.006 QALY, using the utility scores obtained with the SF-36 questionnaire). 


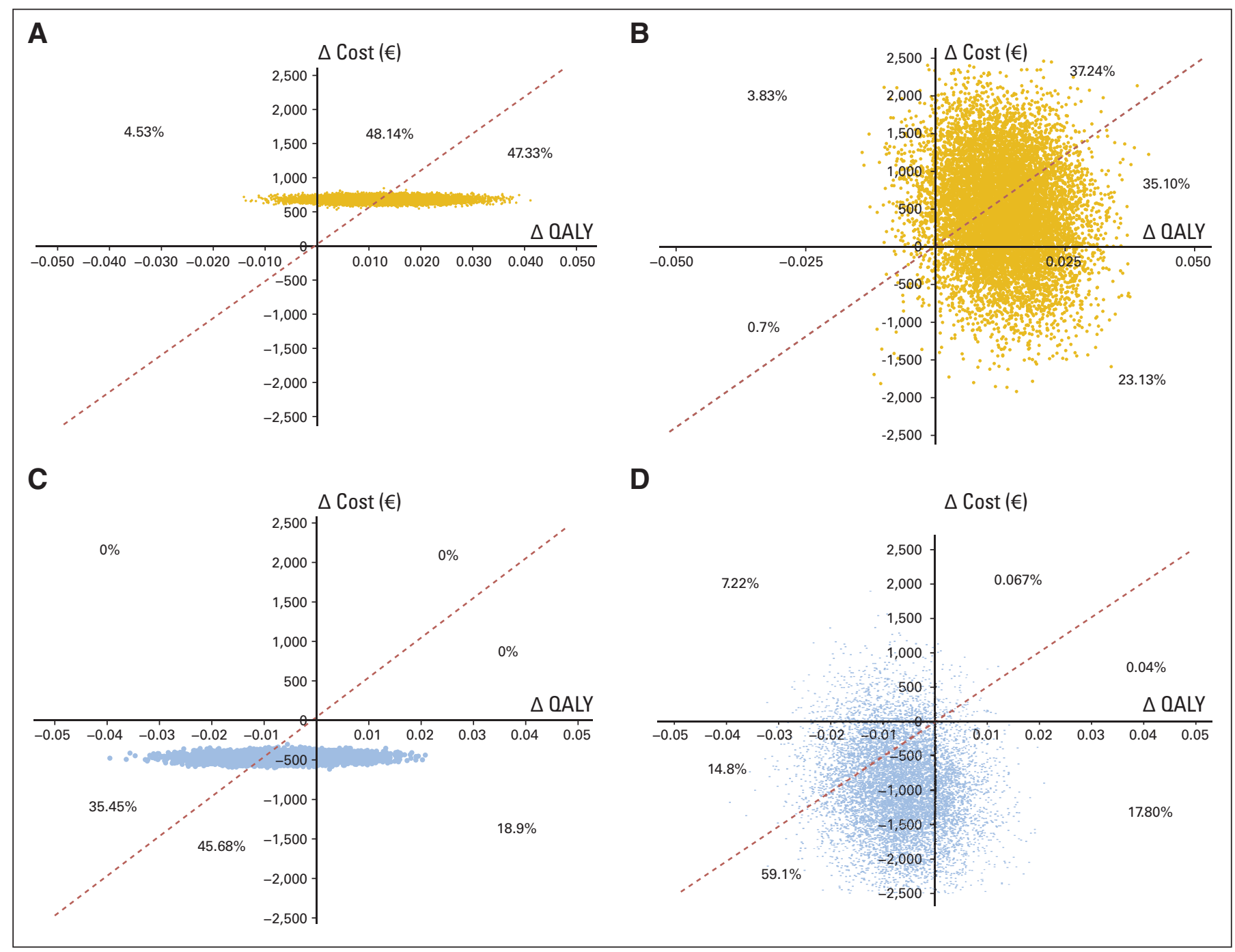

Fig A2. Cost-effectiveness plane. (A) Recombinant human thyroid-stimulating hormone (rhTSH) versus thyroid hormone withdrawal (THW), with direct costs only. With direct costs only, 95\% of the 10,000 iterations were located in the northeast quadrant (rhTSH results in gains in quality-adjusted life-years [QALYs] at additional costs compared with THW), whereas $5 \%$ of the iterations were located in the northwest quadrant (less effective and less expensive). (B) rhTSH versus THW, with total costs (direct and indirect). (C) lodine-131 ( ${ }^{131}$ I) $1.1 \mathrm{GBq}$ versus $3.7 \mathrm{GBq}$, with direct costs only. When only direct costs were considered, $81.1 \%$ of the iterations were located in the southwest quadrant (loss in QALY and decrease in cost), and 18.9\% of the iterations were located in the southeast quadrant (gain in QALY and decrease in cost). (D) ${ }^{131} \mid 1.1 \mathrm{GBq}$ versus $3.7 \mathrm{GBq}$, with total costs (direct and indirect). Results are presented in a radar screen format, where the $x$-axis shows the difference in QALYs and the $y$-axis shows the difference in costs between two strategies (either the two stimulation methods or the two radioiodine activities), where dots represent the 10,000 replications. 


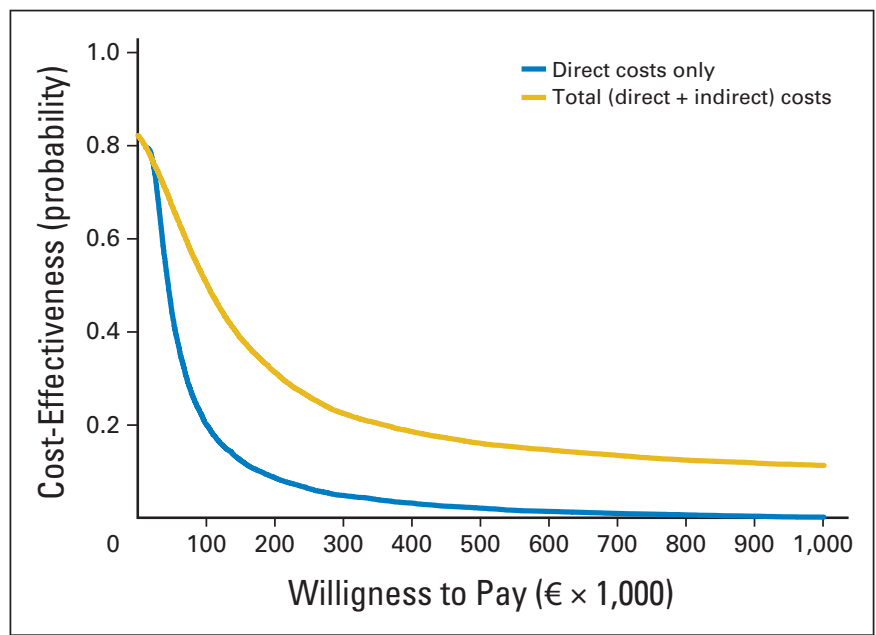

Fig A3. Probability that $1.1 \mathrm{GBq}$ of iodine-131 $\left({ }^{131} \mathrm{I}\right)$ is cost effective compared with $3.7 \mathrm{GBq}$ of ${ }^{131}$ I.

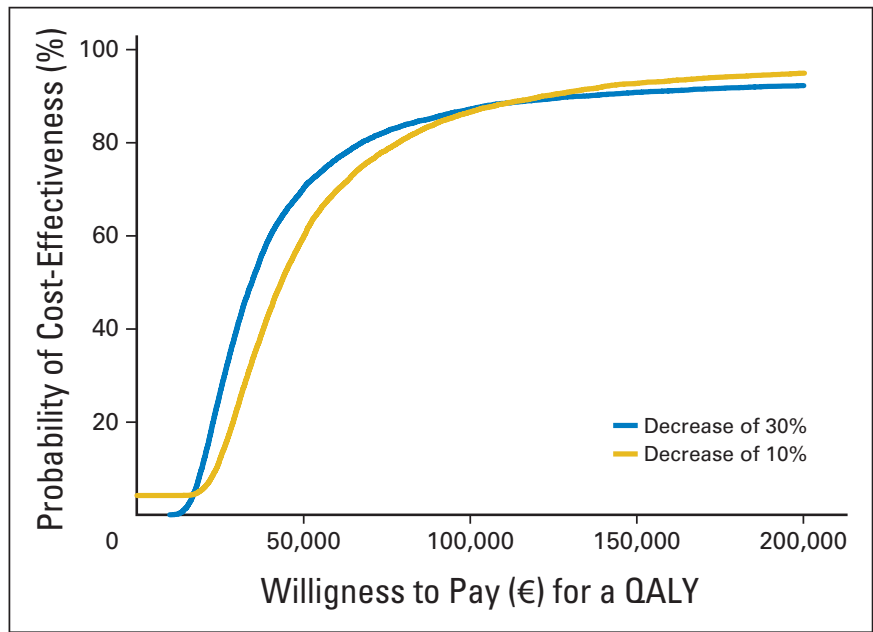

Fig A4. Probability that recombinant human thyroid-stimulating hormone would be cost effective compared with thyroid hormone withdrawal if its price was reduced by $10 \%$ and $30 \%$ (total costs). QALY, quality-adjusted life-year. 